\title{
A descriptive analysis of children's playground injuries in the United States 1990-4
}

\author{
Mick G Mack, Susan Hudson, Donna Thompson
}

\begin{abstract}
Objectives-To review playground injury statistics over a five year period in order to develop an awareness of how and where children in the United States are being injured.
\end{abstract}

Methods-All data are based on the United States Consumer Product Safety Commission's National Electronic Injury Surveillance System (NEISS) for playground related injuries during 1990-4. The surveillance data includes injuries recorded in more than 90 hospital emergency departments located throughout the United States.

Results-Each year there are roughly 211000 preschool or elementary schoolchildren in the United States who receive emergency department care for injuries associated with playground equipment. On average, 17 of these cases result in death. $70 \%$ of all injuries occur on public playgrounds, with nearly one third classified as severe. Swings, climbers, and slides are the pieces of playground equipment associated with $88 \%$ of all NEISS reported injuries. Falls to the surface are responsible for $70 \%$.

Conclusions-NEISS playground injury statistics contribute to our understanding of playground injuries. By identifying where and how children are injured, suggestions can be made in an attempt to make playgrounds safer.

(Injury Prevention 1997; 3: 100-103)

Keywords: contributing factors; playground; playground injuries.

Each year thousands of children receive emergency department care for playground equipment related injuries. In New Zealand, approximately 7400 children require emergency department care with over 1100 being hospitalized, for incidence rates of 930 and 137 respectively, per 100000 children. ${ }^{2}$ In the United States there are over 200000 children treated in emergency departments, for an incidence rate of 398 for children ages $0-4$ and 533 for children 5-15 per $100000 .^{3-5}$ Playground injuries are the leading cause of injuries to students in the school environment. The total cost of these injuries in the United States was estimated to be $\$ 1$ billion in $1992 .^{4}$ An Arizona Department of Health study found that only $72 \%$ of students with reportable injuries were actually taken to the emergency room or to a doctor. ${ }^{6}$ Thus, the number of playground injuries is actually much higher.
Studies of playgrounds in day care centers have reported injury rates per 100000 chile hours ranging from 0.25 to 2.18 , with th majority being above $1.5 .^{7-10}$ Most child cary injuries are relatively minor, the most impor-t tant risk factor being the height of the tallest piece of climbing equipment. ${ }^{78}$ Climbin $\overrightarrow{\mathrm{g}}$ equipment 6 feet or taller had over twice the rate of fall injuries as climbing equipment les than 6 feet. ${ }^{11}$ In another study, the risk of injurijo from falls of heights greater than 1.5 meters was four times that of falls from 1.5 meters of less. ${ }^{1}$ Thus, researchers have suggested that lowering the height of playground equipment may reduce the number of children whe receive emergency department care. ${ }^{178}$ This is supported by additional research indicating that falls to the surface account for $58 \%$ to $70 \%$ of all playground injuries. ${ }^{12} 13$

These findings clearly point to needect changes. Therefore, the purpose of this pape is to review playground injury statistics in the United States over a five year period in aB attempt to provide a broader, more complets picture of how children are injured on play $\Xi$ grounds.

\section{Methods}

All statistics are based on data obtained from the United States Consumer Product Safet Commission's (CPSC) National Electronis Injury Surveillance System (NEISS) for the years 1990-4. NEISS collects data on plays ground product related injuries from $\overline{\mathbf{3}}$. sample of more than 90 hospital emergenci departments. Thus, only emergency roor injury statistics are recorded and nation $\mathrm{S}$ statistics are estimates. The estimated num ber of cases is based on a probability sample The basic factor used to inflate each case is the inverse of the probability of selection of the hospital that treats the case. ${ }^{5}$ The actuaf surveillance data include a number of ele ments (that is, treatment date, patient's age, sex, diagnosis, accident locale, and remark comments).

For the purpose of this analysis, playgrounds are defined as designated areas where station $b$ ary or manipulative equipment is located to facilitate a child's physical, emotional, sociaf and intellectual development. Public play grounds include all play areas open to the general public, including schools, parks, apari ment complexes, child care centers, an restaurants. Similar to previous studies base on NEISS data, injuries are classified accord $\$$ ing to the specific type of play device involved (that is, swing, slide, merry-go-round, etc). Other components did not generally appear to contribute to the incident. ${ }^{1214}$ 
From April through December 1988, the CPSC conducted an in-depth investigation on a systematically selected sample of NEISS playground incidents. ${ }^{14}$ This follow up investigation found that about $15 \%$ of the verified cases were 'out of scope', that is, the injuries did not involve playground equipment. Thus, the projected national estimates in this study are adjusted to reflect this finding.

Information on playground equipment related fatalities was obtained from data reported to the CPSC for the years 1991 through 1995. These data were obtained from a review of NEISS and the CPSC's files of death certificates, consumer complaints, and newspaper clippings. Therefore, the deaths do not represent a complete count of all playground related deaths but are useful as broad indicators of some of the factors involved in these deaths.

\section{Results}

The number of playground injuries remained fairly constant over the five year period. Each year, there are approximately 211150 preschool and elementary schoolchildren in the United States who receive emergency department care for injuries involving playground equipment (see table 1). Nearly $70 \%$ of these occur on public playgrounds.

Boys are involved in a slightly higher percentage of NEISS reported playground injuries $(53.5 \%)$ than are girls $(46.5 \%)$. These differences are slightly more pronounced for preschool aged children-boys, $56.1 \%$. May, June, and September $(14.4 \%, 12.0 \%$, and $12.0 \%$ respectively) are the months with the highest percentage of injuries, while January, December, and February $(2.5 \%, 2.6 \%$, and $3.6 \%$ ) have the lowest.

On average, there are 17 playground related deaths each year in the United States, $67 \%$ of which occur on home playgrounds. Strangulation from ropes, clothing, or strings on clothing, account for $49 \%$ of these deaths. Falls to

Table 1 Estimated playground injuries in the United States, 1990-4 by body part and type

\begin{tabular}{llll}
\hline & Ages $0-4$ & Ages 5-14 & Total \\
\hline Mean No/year & 64180 & 146970 & 211150 \\
Body part (\%) & 60 & 30 & 39 \\
Head/face & 21 & 43 & 36 \\
Arm/hand & 12 & 15 & 14 \\
Leg/foot & 7 & 12 & 11 \\
Other & 21 & 35 & 29 \\
Nature of injury (\%) & 38 & 17 & 24 \\
$\quad$ Fracture & 21 & 23 & 23 \\
Laceration & 6 & 14 & 12 \\
Contusions/abrasions & 6 & 3 & 4 \\
Strain/sprain & 6 & &
\end{tabular}

the surface were reported in another $24 \%$, while $11 \%$ involved equipment falling on the individual. Entrapment (3.5\%) or being struck by a swing $(3.5 \%)$ were also contributing factors in a number of incidents. All other reported deaths were isolated occurrences, such as being struck by rotating playground equipment, face buried in the sand, and hitting the swing set; $62 \%$ of the deaths involved boys, $38 \%$ girls.

\section{SEVERITY AND TYPES OF INJURIES}

The head and face area was involved in the majority of injuries to children $0-4$, while the most commonly injured area was the arm and hand for the 5-14 age group. Approximately $35 \%$ of the injuries were classified as severe (that is, concussions, dislocations, fractures, internal injuries, amputations, and crushings). Seventeen per cent were moderately severe (that is, ingestions, foreign body, hematoma, dental injuries, punctures, strains, sprains, hemorrhage, avulsion, dermatitis, conjunctivitis) and $48 \%$ were relatively minor (that is lacerations, contusions, and abrasions). However, it should be noted that all injuries were severe enough to prompt a visit to an emergency room and about $3 \%$ required hospitalization.

The most common types of injuries have remained relatively constant over this period. The most common diagnosis was fractures, followed by lacerations, contusions, and strains. Internal injuries comprised the fifth most prevalent diagnosis.

Further analysis reveals that the most common diagnosis varies from one piece of equipment to another. Fractures were predominant for climbers each year, whereas injuries associated with slides tended to vary between fractures and lacerations. Conversely, the most prevalent injury associated with swings was lacerations, followed by fractures, and the most common seesaw injuries were lacerations.

\section{EQUIPMENT TYPE}

The NEISS information identifies several types of playground equipment on which injuries occurred: swings, climbing equipment (referred to as climbers), slides, seesaws, merrygo-rounds, 'other' equipment, and 'equipment not specified'. Other equipment includes items such as sliding poles, sandboxes, spring rockers, tunnels, bridges, and ropes. Equipment not specified includes injuries which did not identify a particular piece of equipment.

As illustrated, swings, climbers, and slides are associated with the majority of injuries,

Table 2 Distribution of injuries by type of equipment and age, 1990-4

\begin{tabular}{|c|c|c|c|c|c|c|c|}
\hline \multirow[b]{2}{*}{ Equipment } & \multicolumn{3}{|c|}{ Ages $0-14$} & \multicolumn{2}{|c|}{ Ages 0-4 } & \multicolumn{2}{|c|}{ Ages 5-14 } \\
\hline & Mean & Rate & $95 \% C I$ & Mean & $\overline{\text { Rate }}$ & Mean & Rate \\
\hline $\begin{array}{l}\text { Swing } \\
\text { Climber } \\
\text { Slide } \\
\text { Seesaw } \\
\text { Merry-go-round } \\
\text { Not specified } \\
\text { Other equipment }\end{array}$ & $\begin{array}{l}75375 \\
54755 \\
42920 \\
8175 \\
4000 \\
8885 \\
6995\end{array}$ & $\begin{array}{l}138 \\
120 \\
78 \\
15 \\
7 \\
16 \\
13\end{array}$ & $\begin{array}{l}129 \text { to } 146 \\
109 \text { to } 132 \\
74 \text { to } 83 \\
13 \text { to } 17 \\
6 \text { to } 8 \\
13 \text { to } 19 \\
11 \text { to } 14\end{array}$ & $\begin{array}{l}24025 \\
12005 \\
19865 \\
2850 \\
980 \\
2355 \\
2120\end{array}$ & $\begin{array}{l}128 \\
64 \\
106 \\
15 \\
5 \\
13 \\
11\end{array}$ & $\begin{array}{l}51350 \\
53750 \\
23055 \\
5325 \\
3020 \\
6530 \\
4875\end{array}$ & $\begin{array}{l}143 \\
150 \\
64 \\
15 \\
8 \\
18 \\
14\end{array}$ \\
\hline
\end{tabular}


nearly $88 \%$ (see table 2 ). Seesaws and merrygo-rounds are the other two major pieces of equipment involved but they account for less than $6 \%$. For young children, swings have the highest incidence rates per 100000 (based on United States census figures for 1990) whereas climbing equipment has the highest incidence rates for school age children.

The percentages of severe, moderately severe, and minor injuries also vary according to the type of equipment involved (see table 3 ). Minor injuries were the most common classification for the majority of the equipment including seesaws, swings, and slides. The sole exception is climbers, where the most common classification was severe. Due to the lack of definitive data in this area, merry-go-rounds were included in other equipment.

\section{CONTRIBUTING FACTORS}

Remarks and comments describing each injury were also analyzed to ascertain factors contributing to the incident. Because of the limited information contained in each NEISS remark, contributing factors were restricted to: (1) falls to the surface; (2) falls to the equipment; (3) hit by the equipment; (4) ran into the equipment; and (5) others. For example, the classification of falls to the surface was based on phrases such as 'fell from (equipment)', 'fell onto (surface)', 'fell off (equipment)', and 'landed on (surface)'. It should be noted that $3 \%$ of the NEISS comments had unknown contributing factors and were not included in the analysis. Because the various pieces of playground equipment have differing contributing factors, not all classifications are used in each analysis (see table 4).

As illustrated, falls to the surface were the leading contributing factor. When all pieces of equipment are combined such falls were a contributing factor in $70 \%$. This percentage is the result of the major pieces of equipmentswings, climbers, and slides, which account for $88 \%$ of all injuries. The large percentage for climbing equipment is noteworthy because slightly over $85 \%$ of these injuries involve a fall to the surface. However, while the end result was a fall to the surface, it is often

Table 3 Severity of injuries by type of equipment; values are $\%$

\begin{tabular}{llll}
\hline Equipment & Severe & Moderately severe & Minor \\
\hline Swing & 32 & 16 & 52 \\
Climber & 43 & 17 & 40 \\
Slide & 32 & 19 & 49 \\
Seesaw & 27 & 14 & 59 \\
Not specified & 28 & 22 & 50 \\
Other equipment & 20 & 23 & 57 \\
\hline
\end{tabular}

unclear what actually caused the fall. It could be lack of maintenance, inadequate supervision, or inappropriate age design.

Another major contributing factor for man pieces of equipment appears to be falls ont equipment $(9 \%)$ such as slides, seesaws, othe equipment, and merry-go-rounds.

A third factor is being hit by the equipmente This is especially consequential for swings and seesaws. Nearly $21 \%$ of all swing injuries involve either being hit by the swing or b someone sitting in the swing, and about $26 \%$ of the seesaw injuries listed being hit by the seesaw or running into it.

The final substantial factor is the 'others? classification which includes protrusions and projections. Due to the emphasis in the CPSC's Handbook for Public Playground Safet places on these hazards, the number of injuries related to protrusions and projections was examined separately. ${ }^{15}$ Results indicated that these were contributing factors in $1.3 \%$. Thus? while factors such as protrusions are a hazard that can and should be remedied, they are only involved in a small percentage of injuries.

\section{Discussion}

While no playground will ever be injurys proof, steps can be made to ensure that playing on the playground is a safer, fun filled, learning experience. One of the first steps in this endeavor is to develop an awareness of how and where children are injured.

NEISS provides the most comprehensive statistics currently available in the Unite States. However, the system is not without it shortcomings. First, while based on a system tic probability sample, the national numbers are only estimates. Second, the estimates include only injuries reported to emergenct departments. Thus, the actual number of theso injuries is much higher. ${ }^{6}$ Finally, NEISS surveillance data are often limited and fairl general in nature. While the individual's sex age, diagnosis, and treatment date are almosi always given, the remarks or comments deg scribing the incident are typically vague. For example, rarely is much information provide about the playground, such as 'was pushed of a 6 foot slide onto pea gravel landing on shoulder'. More common are comments like 'Mom said she fell off the swings at school w' Thus, we are unable to obtain vital informatio that would more accurately describe othe contributing factors such as unacceptable sue face materials, lack of maintenance, or inadequate supervision.

Overall, the results are consistent with previous NEISS based studies. ${ }^{12}{ }^{14}$ For exam?

Table 4 Contributing factors by type of equipment; values are \%

\begin{tabular}{|c|c|c|c|c|c|c|c|c|}
\hline Contributing factors & No of cases in NEISS & Swings & Climbers & Slides & Seesaws & Merry-go-rounds & Not specified & Other equipment \\
\hline $\begin{array}{l}\text { Falls to surface } \\
\text { Hit by equipment } \\
\text { Falls to equipment } \\
\text { Ran into equipment } \\
\text { Others }\end{array}$ & $\begin{array}{l}19082 \\
2068 \\
2454 \\
486 \\
3096\end{array}$ & $\begin{array}{l}62.9 \\
20.8 \\
2.9 \\
\text { N/A } \\
13.4\end{array}$ & $\begin{array}{l}85.2 \\
\text { N/A } \\
8.8 \\
2.5 \\
3.5\end{array}$ & $\begin{array}{l}68.3 \\
\text { N/A } \\
17.6 \\
\text { N/A } \\
14.1\end{array}$ & $\begin{array}{l}53.8 \\
23.9 \\
15.3 \\
\text { N/A } \\
7.0\end{array}$ & $\begin{array}{l}57.8 \\
\text { N/A } \\
18.5 \\
\text { N/A } \\
23.7\end{array}$ & $\begin{array}{l}60.9 \\
\text { N/A } \\
21.3 \\
5.0 \\
12.8\end{array}$ & $\begin{array}{l}29.2 \\
\mathrm{~N} / \mathrm{A} \\
22.4 \\
35.9 \\
12.5\end{array}$ \\
\hline
\end{tabular}

$\mathrm{N} / \mathrm{A}=$ not applicable (was either not appropriate or was included in the 'others' because of the limited number of cases). 
ple, injury patterns were not significantly different for boys and girls. Younger children were more likely to suffer injuries to the head and face, while the most commonly injured body part for older children was the arm and hand. Children under age 5 were most frequently injured on swings, and schoolchildren were most often injured on climbing equipment. It is also interesting to note that the percentage of injuries per month increases in September, which is the traditional start of school in most parts of the United States.

\section{Implications for prevention}

An in-depth analysis of the factors involved in playground related injuries for specific pieces of equipment revealed that the majority of injuries involve a fall to the surface. Thus, attention to the proper depth and type of surfacing located under and around equipment should be a top playground management priority. This is especially pertinent for climbing equipment, which tends to be taller and poses a greater risk of injury. ${ }^{11}$

According to the United States CPSC guidelines, acceptable playground surfacing materials include wood chips, rounded gravel, sand, shredded rubber, or a variety of synthetic surfaces. ${ }^{15}$ Hard materials, like asphalt and concrete, are unsuitable surface materials. Likewise, earth surfaces such as dirt, turf, and grass, are unacceptable because their shock absorbing properties vary depending on wear and climatic conditions. Specific surface material depths should be proportionate to the height of the equipment. However, a 12 inch depth of loose fill materials is a good guideline for equipment up to 8 feet in height. In general, the surfaced area under and around playground equipment should extend a minimum of 6 feet in all directions from the edge of stationary equipment. ${ }^{15}$ Slides and swings require different fall zone areas because of the child's momentum. Fall zones for slides should be 4 feet taller than the slide, with a minimum of 6 feet. Fall zones for swings are twice the height of the pivot in front and in back of the swing. Once adequate surfacing is installed, it must be regularly inspected and maintained.

Nearly one fourth of the swing injuries involve being hit by the moving swing. Therefore, it appears that swing safety should include supervision and education so that the number of children who play too close to moving swings can be reduced. Similarly, $36 \%$ of the 'other' equipment injuries involve a child running into the equipment. Perhaps by providing additional education and supervision, some of these injuries could also be prevented.

Two key elements of supervision are foresight and control (SD Hudson, D Thompson,
MG Mack, unpublished paper). It is the duty of the supervisor to protect children from the foreseeable risk of unreasonable harm. ${ }^{16}$ As such, supervisors must visually survey the area before each play period looking for foreign objects, broken equipment, and inadequate surfacing. Secondly, supervisors must actively control the environment. According to a noted safety expert, Richard Borkowski, 'Supervision is first, last, and always a matter of being there-being in and around the area of activity. It's being close enough to watch, to control, and to offer the safest environment possible. ${ }^{17}$

Playing on playgrounds should be a fun filled learning experience for all children. Thus, steps must be taken to provide play environments where children are able to take safe challenges and risks which push their minds and bodies to new limits.

This publication was supported by Grant Number U17/CCU 712119-02 from the Centers for Disease Control and Prevention. The contents of this article are solely the responsibility of the authors and do not necessarily represent the official views of the CDC.

The authors wish to thank the following individuals for their assistance in analyzing the data: Phyllis Boelts, Roberta Becker, Sheila Sires, and Stacy Pierce.

1 Chalmers DJ, Marshall SW, Langley JD, et al. Height and surfacing as risk factors for injury in falls from playground equipment: a case-control study. Injury Prevention 1996; 2: $98-104$.

2 Chalmers DJ, Langley JD. Epidemiology of playground equipment injuries resulting in hospitalization. $\mathcal{F}$ Paediat equipment injuries resulting in hos

3 Sosin DM, Keller P, Sacks J, Kresnow MJ, van Dyck PC Surface-specific fall injury rates on Utah school playgrounds. Am f Public Health 1993; 83: 733-5.

4 US Congress, Office of Technology Assessment. Risks to students in school. Washington, DC: US Governmen Printing Office, 1995.

5 US Consumer Product Safety Commission. NEISS data highlights. Washington, DC: US Government Printing Office, 1992.

6 Arizona Department of Health Service, Community and Family Health Services, Office of Women's and Children's Health. A study of the nature, incidence, and consequences of elementary school playground-related injuries. consequences of elementar

7 Briss PA, Sacks J, Addiss DG, Kresnow M, O'Neil J. A nationwide study of the risk of injury associated with day care center attendance. Pediatrics 1994; 93: 364-8.

8 Briss PA, Sacks J, Addiss DG, Kresnow M, O'Neil J. Injuries from falls on playgrounds: effects of day care center regulations and enforcement. Arch Pediatr Adolesc Med 1995; 149: 906-11.

9 Gunn WJ, Pinsky PF, Sacks JJ, Schonberger LB. Injuries and poisonings in out-of home child care and home care. $A m$ $\exists$ Dis Child 1991; 145: 779-81.

10 Sacks J, Smith D, Kaplan KM, Lambert DA, Sattin RW, Sikes $\mathrm{K}$. The epidemiology of injuries in Atlanta day-care centers. $f A M A$ 1989; 262: $1641-5$.

11 Sacks JJ, Holt KW, Holmgreen P, Colwell LS, Brown JM. Playground hazards in Atlanta child care centers. $A m$ f Public Health 1990; 80: 986-8.

12 Tinsworth DK, Kramer JT. Playground equipment-related injuries and deaths. Washington, DC: US Consume Product Safety Commission, 1990.

13 Frost JL. Young children and playground safety. In Wortham SC, Frost $\mathrm{JL}$, eds. Playgrounds for youn children: national survey and perspectives. Reston, VA AAHPERD, 1990: 29-48.

14 Tinsworth DK, Kramer JT. Playground equipment-related injuries involving falls to the surface. Washington, DC: US Consumer Product Safety Commission, 1989.

15 US Consumer Product Safety Commission. Handbook for public playground safety. Washington, DC: US Consumer public playground safety. Washington,

16 Carpenter LJ. Perfect or perilous: when is a teacher negligent? Strategies 1994; March-April: 23-5.

17 Borkowski R. Safety in school: sports and fitness. Portland, ME: J Weston Walch, 1991. 